\title{
Cross-American Experiences in an Ambitious Energy Reduction and Policy Implementation Project
}

\author{
THOMAS SPIEGELHALTER \& CAMILO ROSALES \\ Florida International University
}

This paper is a summary of cross-American expe-
riences while researching and implementing a
considerable energy reduction grant in three Latin
American municipalities: Valdivia, Chile; Goiania,
Brazil, and Port of Spain in Trinidad and Tobago. The
project involves over 400 buildings in three different
bioclimatic zones. The grant's purpose is to demon-
strate how no-cost or low-cost strategies could be
deployed as efficient examples of energy savings and
greenhouse gas reduction in municipal buildings. The
program, conducted through pilot projects, has been
designed to influence many other cities in the partici-
pating countries and beyond.

\section{INTRODUCTION}

The three year grant finishing in September 2016 has been carried out with the help of three partner universities: Universidad Austral in Valdivia, Chile (UACh); the Universidade Federal de Goias in Goiania, Brazil (UFG); and The University of the West Indies in Trinidad and Tobago (UWI). The three universities involve the participation of architecture and engineering professors and students. The combined expertise in each geographic area, gave the teams considerable capacity to act on the realities of each municipality and individually select what is practical, expeditious, relevant and efficient for each project. The ECPA grant (which stands for Energy and Climate partnership of the Americas) was launched by the Obama administration as a means for directly transferring technology knowledge to end users; it is sponsored by the U.S. Department of State, Bureau of Western Hemisphere Affairs based in Washington, D.C. This grant is managed by Florida International University, which is located in a subtropical climate zone in South Florida with notably experienced faculty in international architectural and engineering practices.

The paper analyzes the disglobal realities between U.S. based research and local practices. Even with an open mindset, the cultural differences, labyrinthine bureaucracies, and the variety of building practices and codes have been bewildering. But many lessons and opportunities have also been found. Among those is the different attitude to thermal comfort among the three countries, and especially between our Latin American case studies and the United States. While benchmarking baseline consumption with sensing equipment and digital simulations an real world building energy data calibrations, we have found much lower energy consumption per square meter in Latin America than in the United States. This has made us reconsider our own green policies and how different environmental attitudes would psychologically influence building energy usage despite similar thermal conditions.

\section{SELECTION OF MUNICIPALITIES}

Florida International University and its partner universities in Chile, Brazil and Trinidad and Tobago, determined the selection of countries, municipalities, and local participants by their ability to provide an advantageous collaborative environment for the analysis, development of relevant recommendations, implementation, and monitoring of the ECPA energy efficiency project.

We also considered these cities for their potential of producing examples for different bioclimatic regions and for the opportunity to test our building energy-reduction methods for different energy policies, weather patterns, building types, building occupancy operations and schedules, building materials and techniques, and types of energy employed, among other variables.

Valdivia/Los Rios in Chile, for example, has more than 50 municipal school buildings built with high seismic standards established after the devastating 1960 earthquake. At 40 degrees South latitude and with a mean temperature of 11 Celsius $(51 \mathrm{~F})$, its main challenge is heating. Firewood, often used in salamander type stoves, provides the largest percentage of heating energy; followed by oil and gas boilers and electric heaters. Valdivia's climate is similar to other regions of Southern Chile and many Andean cities in South America.

In contrast, Port of Spain, located in an oil and petroleum rich Caribbean country, exemplifies the other extreme: at 10 degrees North latitude and with a mean temperature of 26 Celsius (79 F), the main environmental challenge for buildings is dehumidification and cooling. With ample supplies of liquefied natural gas and vast oil reserves, T\&T's main energy supply for air conditioning and ventilation in buildings is oil and gas-generated electricity. T\&T shares a similar climate with much of the Caribbean Basin including Central 

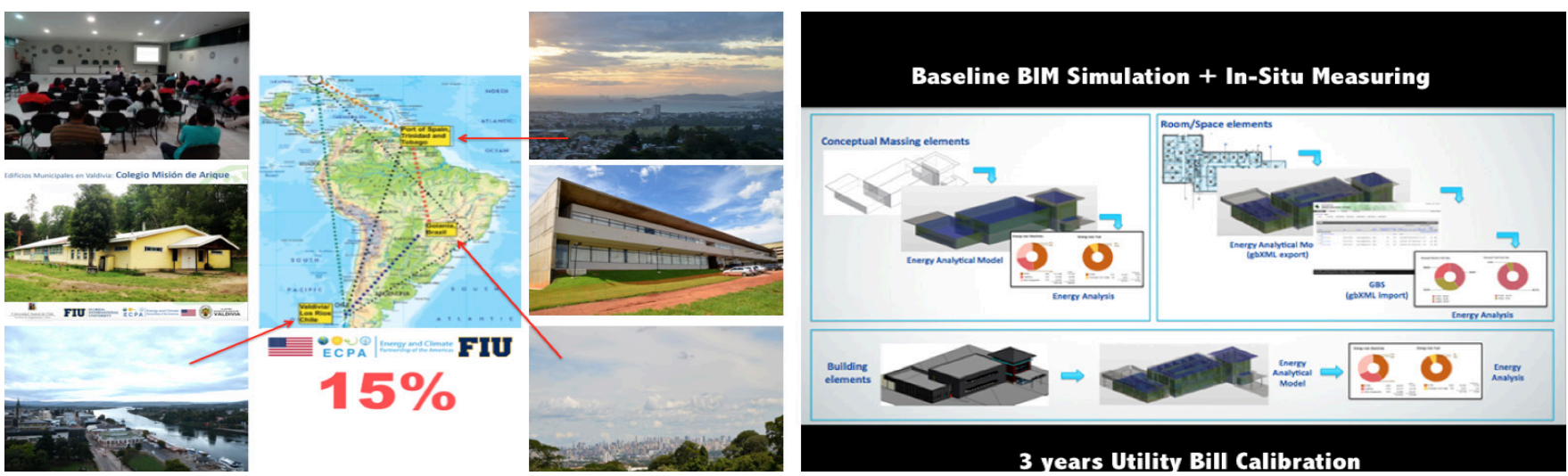

Figure 1: ECPA locations in South America with baseline BIM Simulations and In-Situ measuring. Authors: Thomas Spiegelhalter, Camilo Rosales, 2/1/2015.

America and the coastal region of Colombia and Venezuela.

Finally, Goiania, the capital of the state of Goiás in Central Brazil (and fairly close to Brasilia), is located at 17 degrees South latitude and has a high temperature average of 27 Celsius ( $80 \mathrm{~F}$ ) for most of the year, but with a few months in the mid-60s. Thus, it needs energy for both cooling and heating. Electricity, the main energy supply, is generated from hydro electrical, nuclear, biofuels, and petroleum power sources. Goiania shares similar climatic conditions with cities located in the vast Central Brazilian plain.

These three municipalities have made a commitment to improve the energy sector. They joined the network of Emerging Sustainable Cities Initiative (ESCI) launched in 2011 by the Inter-American Development Bank (IDB). The $\mathrm{ESCl}$ helps fast growing intermediate cities make more informed planning decisions and take immediate actions toward smart and sustainable urban development. It also promotes links, partnerships, exchange of experiences and best practices among local leaders and organizations committed sustainability and provides online file sharing.

Although the three selected countries represent relatively stable and progressive economies, their socio-economic realities, in varying degrees, favor cost-effective technologies that would permeate and stay in their communities. From the start our aim has been to use simple passive and active economical technologies and systems supported by local labor and materials, and use foreign-manufactured equipment and systems only when there are clear short and longterm benefits that justify their introduction (Fig.1).

\section{GENERAL SCOPE OF WORK}

The Scope of Work of this project consists of four major objectives: The first objective was to conduct a building energy efficiency policy analysis and a baseline assessment of municipal building energy use in the three selected municipalities to develop relevant recommendations for improved building energy efficiency guidelines and standards. The final challenge is to reduce $10 \%$ to $15 \%$ of building energy consumption and reduce Greenhouse Gases in the municipal real estate of each participating city.
The second objective is to influence municipal governments for adopting new sustainable codes, especially those related to building energy and water consumption.

The third goal is to train the entire municipal personnel about building energy-saving practices. These training sessions include the understanding of providing thermal comfort for the building occupants by applying appropriate passive strategies for controlled shading, solar illumination, harnessing daylight and redirecting daylight into offices and classrooms; fixing thermal bridges and air leakages in the building envelope, and providing efficient natural ventilation practices. The training also includes improved active strategies for the proper operation, and maintenance of AC and/or HVAC equipment, thermostats and occupancy sensor, and other building energy and water operating devices and systems (Fig.2).

The fourth goal is promoting the best practices encountered through a variety of outlets including public media, promotional competitions in science fairs or similar, social media, and various other websites associated with these programs.

From the start, the program has been consensus-based and market-driven in each participating municipality. A relevant number of stakeholders has been invited to participate, including municipal personnel (technical and non-technical), local builders, lenders, developers, utility providers, related governmental agencies and broad based focus groups from the general public.

Special attention has been paid to the promotion of energy efficiency policies and of a new voluntary rating and certification system that has been selected by each participating municipality.

Our teams have recommended zoning incentives, fast-track permitting processes and/or other encouragements for using energy efficiency standards and new voluntary rating systems. In equal fashion, lending institutions have been invited to participate in workshops promoting the benefits of sustainable codes. These training sessions have been also designed to influence financial organizations in easing the construction lending process for green building applicants. 


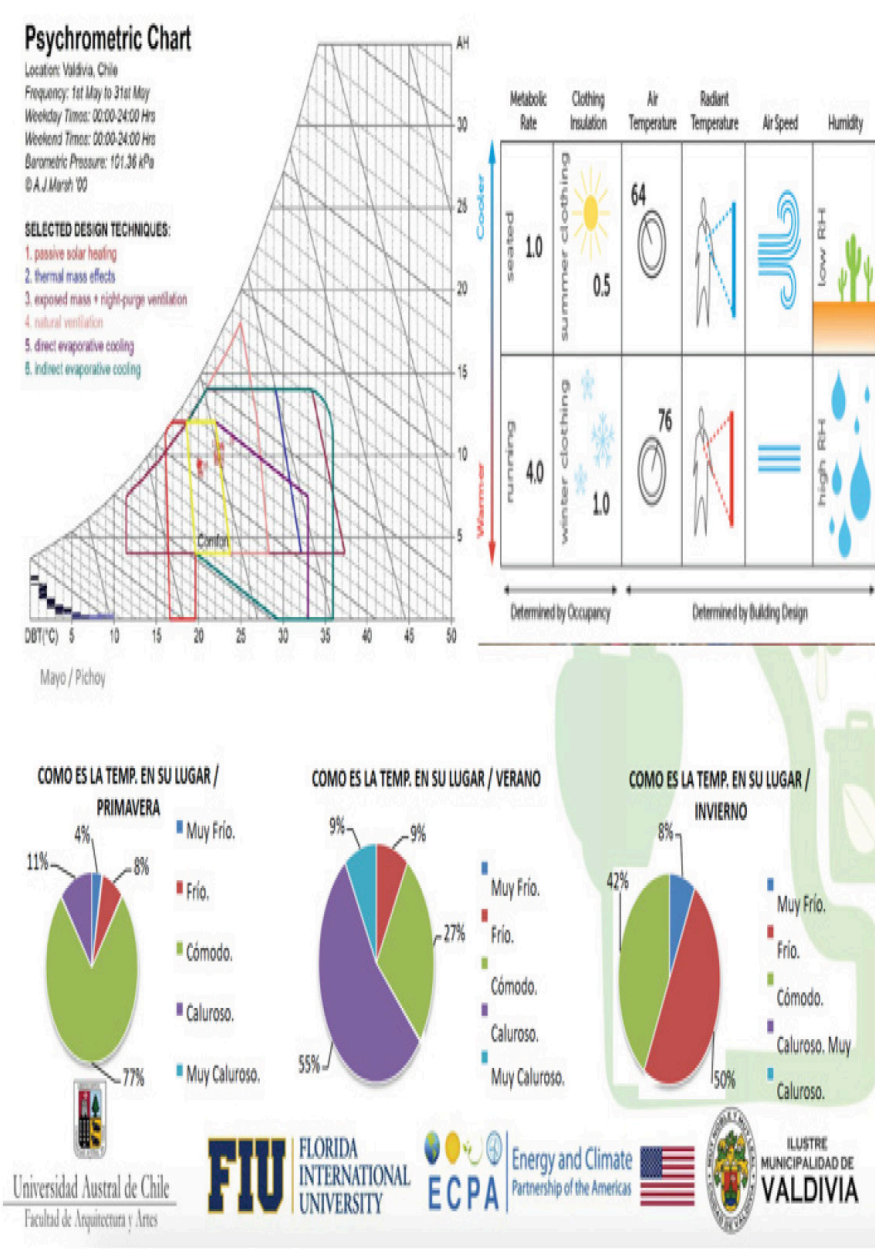

Figure 2: Thermal Comfort Chart and Psychrometrics for the projects in Valdivia, Chile. Authors: Spiegelhalter-Rosalez and Valdivia Team, 3/3/2016

Each municipality have created, and continuously updated, a website specifically designed for recording the project's progress at the completion of each component. As pilot projects are completed, postoccupancy monitoring will be implemented to test initial assumptions and adjust baseline standards. FIU will assist local partners in creating a monitoring system for continuously updating sustainable building codes and directives.

\section{ENERGY BILL ANALYSIS, BIM MODELING WITH ENERGY SAVING RECOMMENDATIONS}

This section summarizes the methods, training procedures for the analysis of the utility and energy bills, analysis of the building systems, building materials, R- and U values, occupancy loads, user schedules, and peak loads variables considered for this project. Collected building data was computed into parameters using 3-D and 4-D Building Information Modelling (BIM) processes for energy, water and $\mathrm{CO} 2$ simulations along with real energy consumption and energy bill data calibrations and validations (Fig. 1,2,3). The entire digital process has been supported by hands-on workshops to implement diagnostic monitoring tools such as real-time data loggers, sensors, infrared devices and meters within certain selected building zones that could help reduce in energy demand. In addition, building user surveys were conducted in the three participating municipalities in Chile, Brazil and Trinidad Tobago).

The compiled real-time data logger information has been used to calibrate the computational master model of the facility with real world energy and water bills; so that, the computer model algorithmically responds to the parametric inputs and changes the same way the building could be expected to respond. This calibration is multiple times checked and validated by simulating a minimum of 3 years or more of past minute-by-minute climate conditions to see if power and energy usage in the model mirrors actual energy power and energy usage in the bills. Once the 3-D computer model is responding like the real building, changes to the passive space conditioning and active energy systems could be simulated with more accurate results.

In general all parametric-algorithmic 3-D/4-D Building Information Modelling (BIM) analysis and recommendation scenarios for energy savings with the suggested yearly Post-Occupancy-Evaluations are based on the following list of national and international methods and protocols:

The mandatory yearly European Directive on the Energy Performance of Buildings (EPBD), 2002/91/EC E.U.,

Building Energy Performance Certification Method (German Energiepass) with the European mandatory Heat and Cooling Load ISO EN 12831 Code Calculation Procedure;

The voluntary U.S. Energy Star Portfolio and Energy Star Rating Procedure and ASHRAE Level 2 and 3 Energy Auditing;

ASHRAE 62.1 Ventilation Rate Procedure, EN ISO 7730, PMV/PPD, EN ISO 14415, ISO TC 159 SC5 WG5;

Thermal Comfort Standard ISO 7730 Ergonomics of the thermal environment and ANSI/ASHRAE Standard 55.

For the digital whole building energy, water and $\mathrm{CO} 2$ analysis and scenario modelling, the following digital tools and platforms were used at FIU and proposed to the ECPA teams that allow real-time cloud service data processing and data exchange:

Autodesk REVIT and REVIT MEP with gbxml plug ins for Green Building Studio; Autodesk Computational Fluid Dynamics (CFD) and Autodesk Flow; Affluent; eQuest; Energy Plus; ArchiCad with gbxml plug ins; Rhino with gbxml plug ins and Elite CHVAC software

The aforementioned steps help in identifying retrofitting strategies and low construction costs to support further investment decisions by the municipalities after this grant concludes. At the end of this 3-year grant all the outcomes of the audits will be recorded in a concise report aimed at recommending owners and management teams about a variety of Energy Efficiency Measures (EEMs), including no cost and/ or low-cost strategies, modifications to occupancy behavior, system controls and building automation, operational changes, and potential capital upgrades with investment payback scenarios to reduce energy usage by $15 \%$. The findings will also include comparable benchmarks of building energy usage ( $\mathrm{kWh} / \mathrm{m} 2 /$ year) in similar climate zones. 


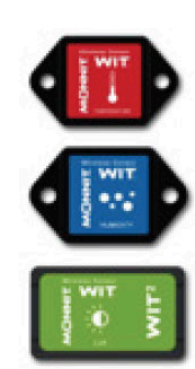

Data Logger Sensors

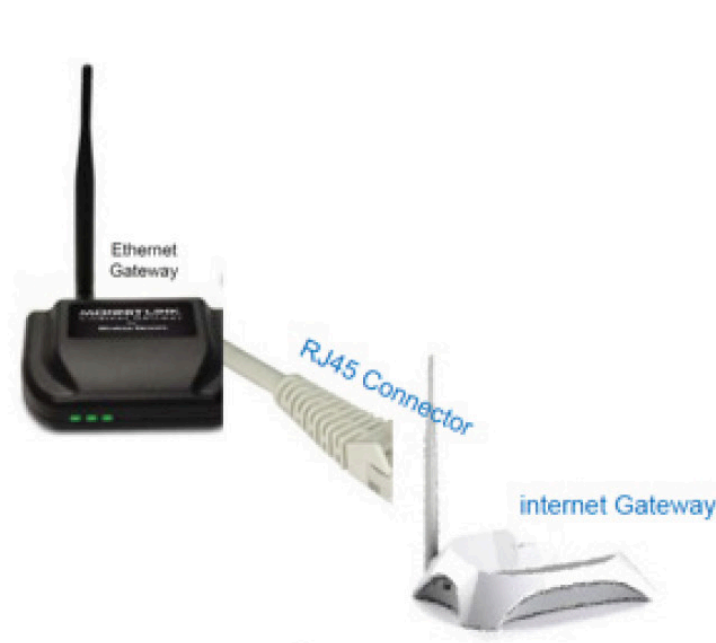

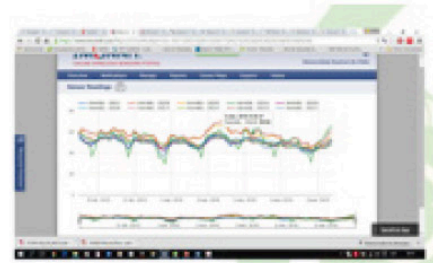

$\mathrm{PC}$ - Internet

$\Delta$ Data Logger Interface

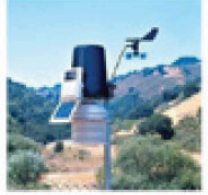

Weather Link Station

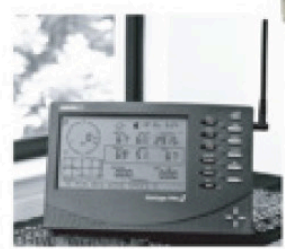

Ethemet Gateway

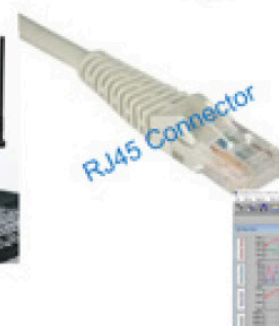

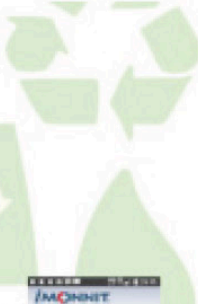
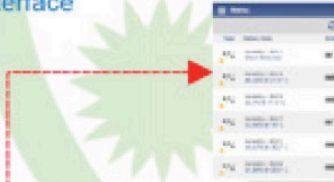

Smart App Data Logger Interface

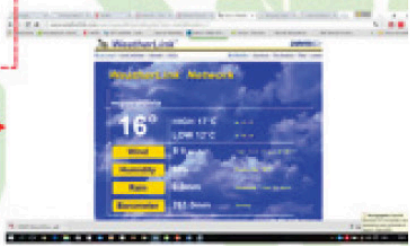

PC - Internet

Weather Link Station Interface

PC - Software

Weather Link Station Interface

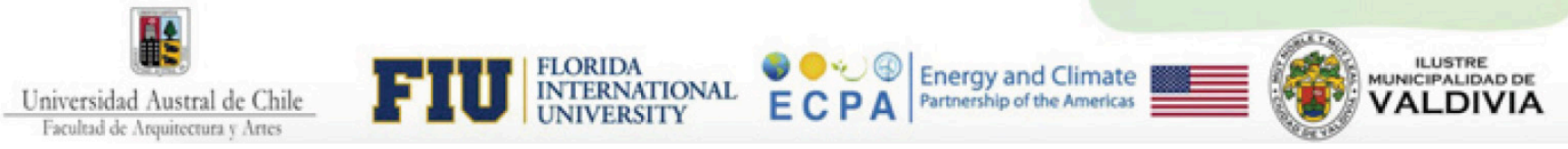

Figure 3: Realtime measuring with sensors, hobos, weather station and data logger processing. Authors: T. Spiegelhalter, Validvia Team, 3/3/2016.

\section{BEHAVIORAL AND CULTURAL DIFFERENCES IN APPLYING THERMAL COMFORT STANDARDS, SETTINGS AND PRACTICES}

One of the most interesting observations we have had so far is the significant difference on how the provision of thermal comfort parameters and practices are handled in each participating municipality as compared to the mandatory ASHRAE 55 standard for HVAC equipped buildings in the United States. We experienced during in situ analysis and while measuring temperature and humidity variables during the building occupancy evaluations that the adaptive relations related to clothing and thermal behavior are significantly different when compared to the U.S. thermal comfort provisions.

For example, we used the ISO 7730 methods for predicting the general thermal sensation and degree of discomfort (thermal dissatisfaction) of building users exposed to hot, humid or moderate thermal environments in a candidate hospital in Goiania, Brazil (Fig. $\mathrm{X}$ ). We found that most of the hospital rooms and zones were based on a very simple principle of temperature and thermal comfort hierarchy. Only the surgery rooms, medical storage and doctor offices were air conditioned, all the other spaces such as the public reception area and the semi-public and private waiting rooms were naturally cross ventilated with accepted maximum temperatures of 28 to 33 Celsius (82 - 91,4 F). One can imagine what those temperatures would cause in the US on complaints to the building operators and management. Using publically available information provided by the Energy Information Administration (EIA), we found that the overall building temperature and humidity levels in the selected countries as compared to the U.S. was much higher.

These results using both current and historical data from The U.S. Energy Information Administration (EIA), shows that over the past thirty years, Americans have had much higher heating and cooling temperature settings than our target countries. This reveals a rather striking example of prolific waste of energy use when compared to the ECPA countries with the exception of some buildings in Trinidad-Tobago. The impact of behavioral patterns to reduce energy consumption has been the biggest energy-reduction knowledge that we have gained in the past 3 years of research (Fig. 2,3 and 4).

\section{BUREAUCRACIES}

We were prepared for bureaucratic delays, unkept promises and perhaps some degree of inefficiency in Latin American municipal agencies. But the situation greatly varied from one country to 

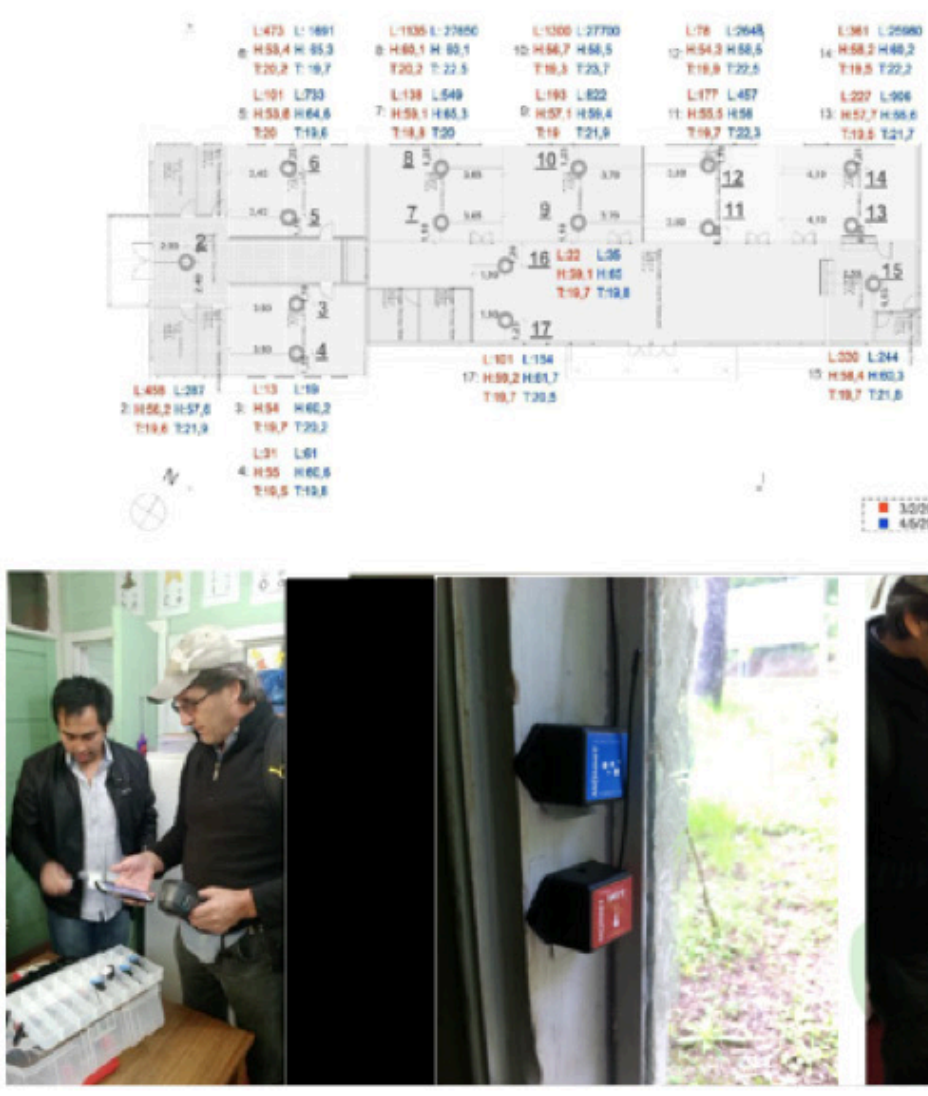

:
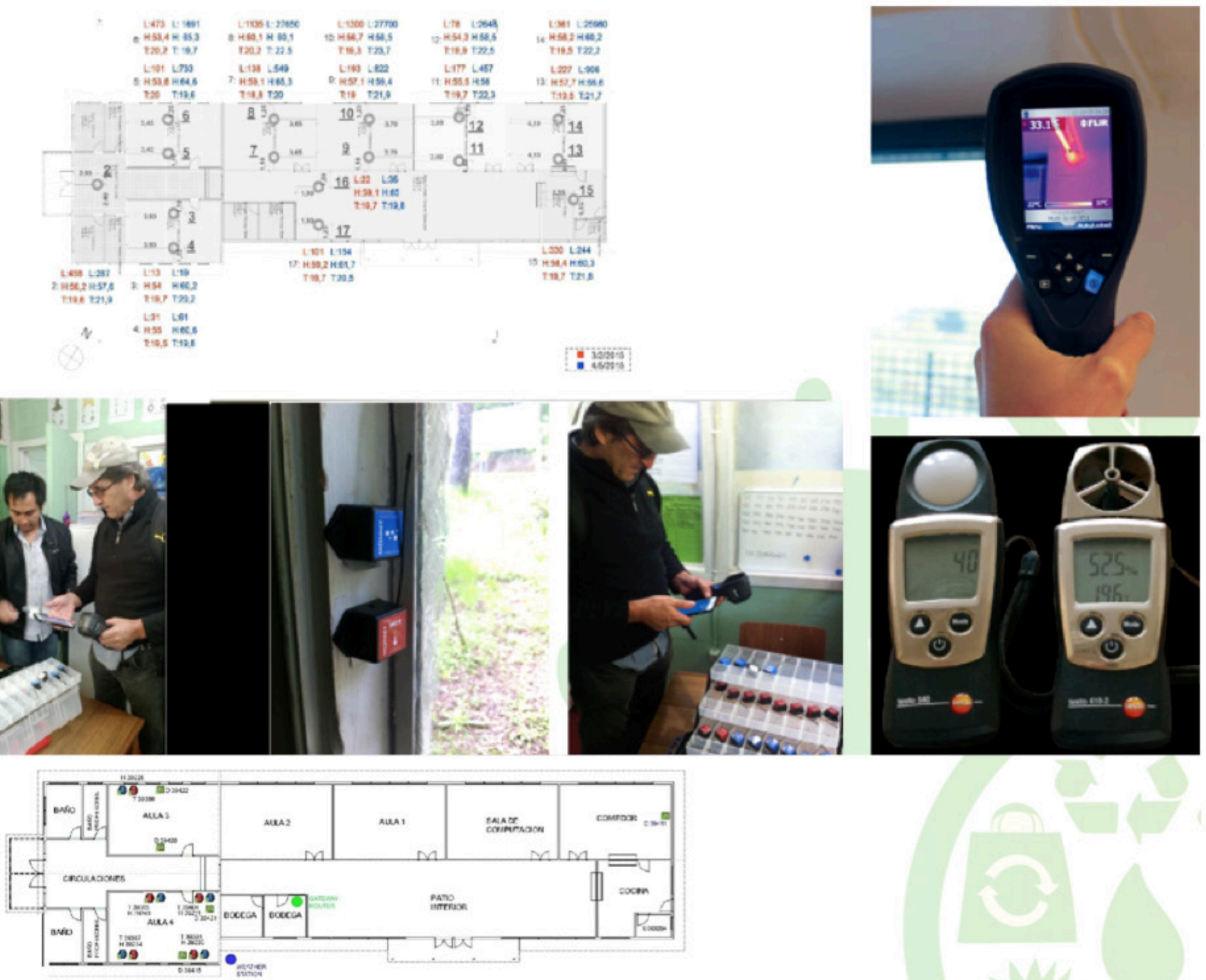

Primera Planta, Colegio Misión de Arique
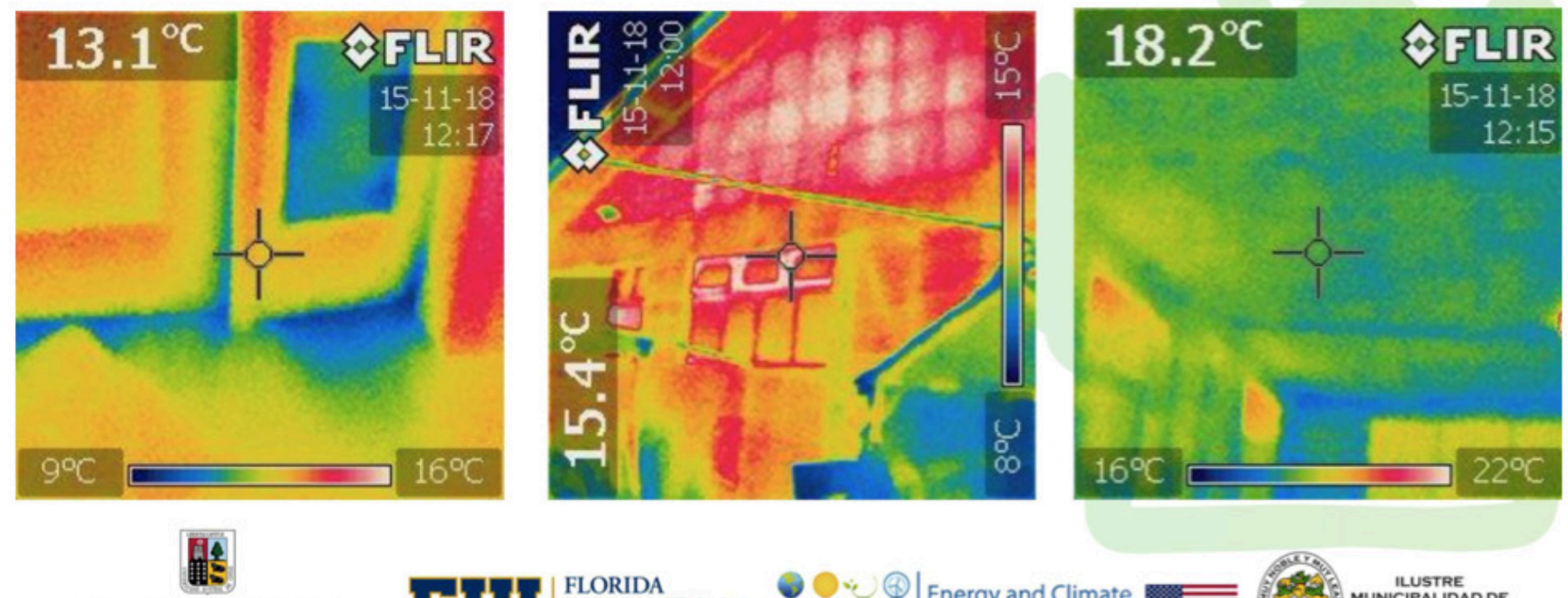

Universidad Austral de Chile Facultad de Arquitectura Y Artes

FLORIDA

INTERNATIONAL UNIVERSITY

E C P A

Energy and Climate
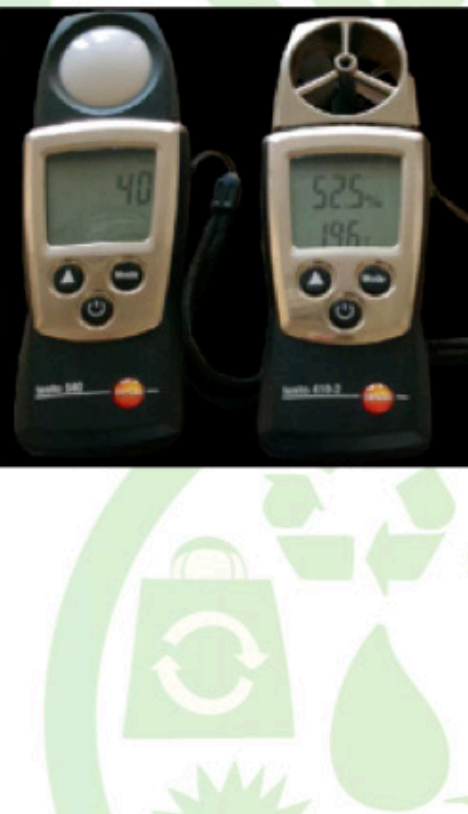
another. In Trinidad and Tobago, the municipality of Port of Spain has a relatively small roll in administering the city. Health and educational concerns are run by semi-independent agencies, as are central government buildings. This lack of cohesiveness or centralization forced us to seek approvals for access, personnel training and for the formulation of green codes with many separate entities making this a laborious and slow process. Added to these difficulties were the fact that some of the municipal buildings are housed in rental properties; this forced us to also seek permissions from several building owners. Seeking funds for implementing our recommendations has run the same fate.

In Goiania, Brazil there is a centralized municipality that controls over 300 buildings, and, as with Trinidad, many of these properties are housed in rented buildings; again, this also forced us to seek approval for collecting data from many different operators. Valdivia, Chile has the most compact municipality consisting mostly of one large municipal office building and approximately 50 schools. Their centralized structure and openness with the general public made our work more efficient and our project there is the most successful to date.

\section{BEST MANAGERIAL PRACTICES AND LESSONS LEARNED}

Each municipality proved so different that the idea of globalization seems foreign and remote. Cultural, political, and economic differences among diverse localities are hard to equalize. Globalization seems to work better at the macro scale, that of international agreements, global finance and trade. We learned the hard way that in projects of this nature it is mandatory to meet with the local actors before the beginning of the program. Perhaps a grand opening night involving most of the key players could have brought the precious opportunity of quickly gaining a sense of the local realities. Securing this sort of information early on could have saved us some precious time and difficulty. 